\title{
Synthesis and Characterization of Methacrylamide Based Hydrogels
}

\author{
Semiha KUNDAKCI ${ }^{1 *}$
}

\begin{abstract}
In this study, it was aimed that produce new polymeric hydrogels and that investigate the equilibrium swelling properties. Chemically crosslinked copolymeric hydrogels, composed of methacrylamide (MAAm) and 2-acrylamido-2-methyl-1-propanesulfonic acid (AMPS) were prepared via free radical copolymerization method. The obtained copolymeric hydrogels were characterized with FT-IR analysis and SEM techniques. In addition, swelling tests $25{ }^{\circ} \mathrm{C}$ were applied to all the synthesized samples and swelling characterization studies were performed. The influences of reaction variables such as monomer/co-monomer composition, crosslinker amount on swelling properties of hydrogels were investigated. When the swelling results are evaluated; It was observed that all polymeric samples showed different swelling and diffusion properties depending on their composition.
\end{abstract}

Keywords: methacrylamide, hydrogel, swelling.

\section{Metakrilamid Esaslı Polimerik Hidrojellerin Denge Şişme Çalışmaları}

ÖZET: $\mathrm{Bu}$ çalışmada, yeni polimerik hidrojellerin üretilmesi ve denge şişme özelliklerinin araştırılması amaçlanmıştır. Metakrilamid (MAAm) ve 2-akrilamido-2-metil-1-propansülfonik asit (AMPS)'den oluşan kimyasal çapraz bağlı hidrojeller, serbest radikal kopolimerleşme yöntemi ile hazırlanmışlardır. Elde edilen kopolimerik hidrojeller FTIR analizleri ve SEM teknikleri ile değerlendirilmiştir. Ayrıca tüm sentezlenen numunelere $25^{\circ} \mathrm{C}$ 'de şişme testleri uygulanmış ve şişme karakterizasyon çalışmaları yapılmıştır. Hidrojellerin şişme davranışları üzerine monomer/yardımcı monomer bileşimi ve çapraz bağlayıcı miktarı gibi reaksiyon değişkenlerinin etkileri araştırıldı. Şişme sonuçları değerlendirildiğinde; tüm polimerik örneklerin bileşimlerine bağlı farklı şişme ve difüzyon özellikleri gösterdikleri belirlenmiştir.

Anahtar kelimeler: metakrilamid, hidrojel, şişme.

\footnotetext{
${ }^{1}$ Semiha KUNDAKCI (Orcid ID: 0000-0001-9584-6129), Department of Chemistry, Faculty of Arts and Sciences, Aydın Adnan Menderes University, 09100-Efeler, Aydın-Turkey

*Sorumlu Yazar / Corresponding Author: Semiha KUNDAKCI, e-mail: skundakci@adu.edu.tr
}

Geliş tarihi / Received:15.02.2019

Kabul tarihi / Accepted:08.04.2019 


\section{INTRODUCTION}

Hydrogels which the major constituent is water are a particular class of polymers. Polymeric hydrogels possess numerous properties such as highly hydrophilic nature, soft and rubbery structure, 3 D network structure, the ability to absorb of water, physiological fluids, dye and heavy metal ions that make them ideal candidates for use in many areas. Hydrophilic groups such as $-\mathrm{OH},-\mathrm{O}=\mathrm{COH},-\mathrm{O}=\mathrm{CNH}$, $\mathrm{O}=\mathrm{CNH}_{2}, \quad-\mathrm{SO}_{3} \mathrm{H}$, etc. that located within the network structure that provides the hydrophilicity of the structure cause significant changes in the swelling and adsorption properties of the polymeric hydrogels. Properties such as structure of polymer, characteristics of swelling medium, polymer-solvent interactions and crosslinker type and amount are some of the variable effecting the water absorption characteristics of ionic hydrogels. Polimeric hydrogels which can be modified according to the desired purpose are polymeric materials with many uses such as food industry, personal care products, biomedicine, separation process and water purification. (Peppas et al., 2000; Ganji et al., 2010; Koetting et al., 2015; Sunitha et al., 2015; Singhal and Gupta, 2016; Wan et al., 2016).

The goal of the present paper was to design methacrylamide-based hydrogels crosslinked with $N, N$ ' methylenebisacrylamide (NMBA) and to study the impact of these polymeric hydrogels on swelling properties. For this purpose, methacrylamide/2-acrylamido-2methyl-1-propanesulfonic acid (MAAm/AMPS) hydrogels having different compositions were synthesized in an aqueous medium with the free radical polymerization reaction. The structural, surface and swelling characteristics of the polymeric samples were examined. The associated swelling parameters commonly used for the characterization of synthesized hydrogels were calculated using dynamic swelling tests at $25^{\circ} \mathrm{C}$ and the mechanism of diffusion was tried to be explained.

\section{MATERIALS AND METHODS}

The monomer (MAAm) used in the present study was purchased from SigmaAldrich. AMPS used as co-monomer was provided by Aldrich Chemical Co., Milwaukee, US. NMBA (Sigma-Aldrich Steinheim, Germany) was used as a crosslinker to ensure cross-linking. Ammonium persulphate(APS) and $N, N, N^{\prime}, N^{\prime}$-tetramethylethylenediamine

(TEMED), which were used as initiators and accelerators, were bought from Merck. Ethyl alcohol was purchased from Sigma-Aldrich.

\section{General procedure for the polymerization of MAAm/AMPS hydrogels}

Copolymeric hydrogels were synthesized from crosslinking of MAAm and AMPS monomers with NMBA using the free radical copolymerization method. In the synthesis stage, initiator (APS) and accelerator (TEMED) were used. The copolymeric hydrogels having different monomer and cross-linker compositions were synthesized. Detailed MAAm/AMPS hydrogels formulations are given in Table 1.

A typical MAAm/50AMPS ${ }_{1}$ synthesis was as follows:

MAAm (1.0 g) was dissolved in a $2.0 \mathrm{~mL}$ water-ethanol mixture $(1: 1 \%)$ at room temperature. AMPS $(50 \mathrm{mg})$ was then added to this solution and stirred until a homogeneous monomer mixture was formed. Then, $0.25 \mathrm{~mL}$ of NMBA $(2 \% \mathrm{w} / \mathrm{v}), 0.2 \mathrm{~mL}$ APS $(5.0 \mathrm{~g} / 100 \mathrm{~mL}$ water) and $0.25 \mathrm{~mL}(1 \% \mathrm{v} / \mathrm{v})$ of the TEMED were added to the mixture, respectively.

After all the components were homogeneously mixed, the resulting mixture was transferred to the PVC straws ( $3 \mathrm{~mm}$ diameter) and then kept at $60{ }^{\circ} \mathrm{C}$ for 30 minutes until polymerization was complete. The long cylindrical copolymeric samples obtained after 
copolymerization were cut into pieces (3-4 mm in length) and the samples were then placed in distilled water to remove any water-soluble monomer and other components that remained unreacted. Distilled water was changed regularly 3 times a day for 4 days. The hydrogels were first dried in air and then dried in vacuo and kept for further use.

Phases of the synthesis and swelling of copolymeric hydrogels were presented in Figure 1 .

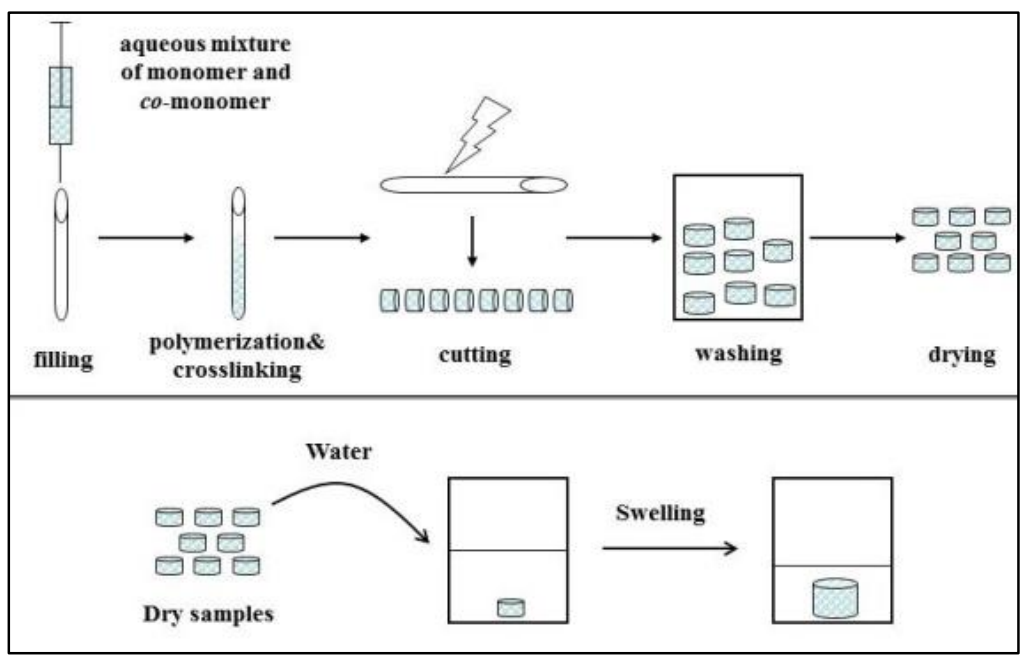

Figure 1. The steps of the preparation and swelling of copolymeric hydrogels.

\section{Synthesis of MAAm/AMPS hydrogels with different compositions}

Figure 2 presents the molecular structure of monomers and their possible binding mechanism. To examine the effect of the amount of MAAm, AMPS and crosslinker on the swelling performance, polymeric samples were prepared in different formulations by applying the above mentioned procedure. Detailed MAAm/AMPS hydrogels formulations are given in Table 1.
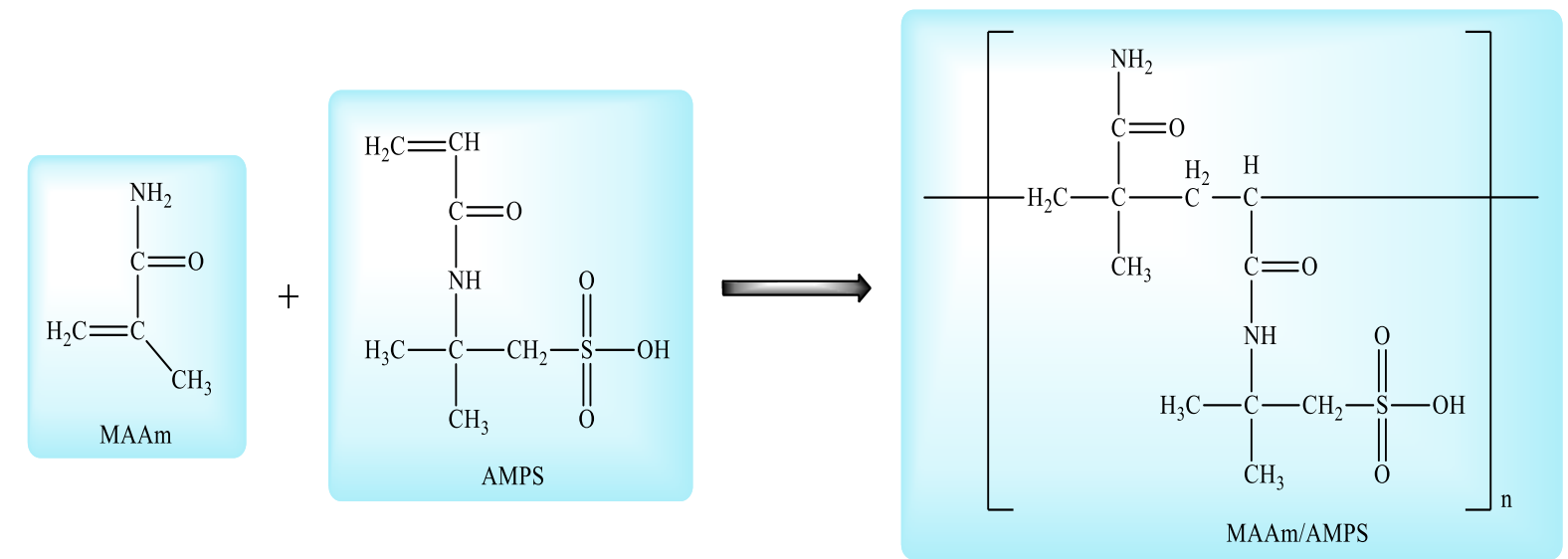

Figure 2. The molecular structure and the probable binding mechanism of monomers. 
Table 1. Combinations of polymeric hydrogels prepared in different formulations

\begin{tabular}{|c|c|c|c|c|}
\hline & Abbreviation & $\begin{array}{l}\text { MAAm } \\
(\mathrm{mmol})\end{array}$ & $\begin{array}{c}\text { AMPS } \\
(\mathrm{mmol}) \times 10^{2}\end{array}$ & $\begin{array}{c}\text { NMBA } \\
(\mathrm{mmol}) \times 10^{2}\end{array}$ \\
\hline \multirow{4}{*}{1} & $\mathrm{MAAm} / 0 \mathrm{AMPS}_{1}$ & \multirow{4}{*}{11,75} & 0.0 & \multirow{4}{*}{1.62} \\
\hline & MAAm/50 $\mathrm{AMPS}_{1}$ & & 24.13 & \\
\hline & MAAm/100 $\mathrm{AMPS}_{1}$ & & 48.25 & \\
\hline & $\mathrm{MAAm} 150 \mathrm{AMPS}_{1}$ & & 72.38 & \\
\hline \multirow{4}{*}{2} & $\mathrm{MAAm} 0 \mathrm{AMPS}_{2}$ & \multirow{4}{*}{11,75} & 0.0 & \multirow{4}{*}{3.24} \\
\hline & MAAm/50 $\mathrm{AMPS}_{2}$ & & 24.13 & \\
\hline & MAAm/100 $\mathrm{AMPS}_{2}$ & & 48.25 & \\
\hline & MAAm/150 $\mathrm{AMPS}_{2}$ & & 72.38 & \\
\hline \multirow{2}{*}{3} & $0.75 \mathrm{MAAm} / 100 \mathrm{AMPS}_{1}$ & \multirow{2}{*}{8.81} & \multirow{2}{*}{48.25} & 1.62 \\
\hline & $0.75 \mathrm{MAAm} / 100 \mathrm{AMPS}_{2}$ & & & 3.24 \\
\hline 4 & MAAm/100/AMPS $_{1.5}$ & 11,75 & 48.25 & 2.43 \\
\hline 5 & $\mathrm{MAAm} / 0 \mathrm{AMPS}_{1.5}$ & 11,75 & 0.0 & 2.43 \\
\hline
\end{tabular}

\section{RESULTS and DISCUSSION}

\section{Characterization of the hydrogels}

Spectroscopic characterization and swelling characterization methods were used for characterization of synthesized hydrogels. In addition, scanning electron microscopy (SEM) micrographs were taken to inform about the surface properties of the crosslinked structures.

\section{FT-IR spectral analysis}

FT-IR/ATR analysis was performed for structural characterization. Functional groups of MAAm/AMPS hydrogel systems with different compositions were examined by FT-IR spectroscopy Thermo Scientific Nicolet is 10 SMARTt FT-IR/ATR (United States of America) using ATR apparatus.

Figure 3 represents the FT-IR spectrum of MAAm and MAAm/AMPS hydrogels were scanned from 400 to $4000 \mathrm{~cm}^{-1}$. In Figure 3 (a), a strong and broad absorption band has been observed at between $3600-3000 \mathrm{~cm}^{-1}$ owing to $\mathrm{N}-\mathrm{H}$ groups of MAAm and AMPS. The peak monitored between $1500-2000 \mathrm{~cm}^{-1}$ shows the tensile vibration of carbonyl $(\mathrm{C}=\mathrm{O})$ groups in the structure of MAAm and AMPS. It is thought that the characteristic peaks at $1000-1500 \mathrm{~cm}^{-1}$ are due to the presence of $\mathrm{C}-\mathrm{C}\left(1300-1500 \mathrm{~cm}^{-1}\right)$ bending vibrations and $\mathrm{C}-\mathrm{N}\left(1000-1300 \mathrm{~cm}^{-1}\right)$ stretching vibration. On the other hand, the peak at $2900-3100 \mathrm{~cm}^{-1}$ show $\mathrm{C}-\mathrm{H}$ stretching of $\mathrm{CH}_{2}$ groups. The peak observed at $1040 \mathrm{~cm}^{-1}$ is typical characteristic peak of the SO groups in the AMPS units. While this peak was not observed in MAAm, it was determined that the intensity of this peak with the amount of AMPS added to the structure increased (Durmaz and Okay, 2000; Barati et al., 2013; Kousar et al., 2018). The FT-IR spectra of original MAAm and AMPS are shown in Figure 3 (b).

\section{SEM analysis}

Investigation of surface morphologies of synthesized polymeric samples was performed using scanning electron microscopy (Carl Zeiss 300 VP). Dry polymeric hydrogels were coated with an electrically conductive material (gold) prior to analysis. (Quorum Q150 RES).

The micrographs of cross-linked MAAm and MAAm/AMPS hydrogels containing 1.0 and $2.0 \mathrm{v} \%$ of crosslinker are depicted in Figure 4. It is seen that all polymeric hydrogels show a porous surface. Furthermore, the SEM images indicate that the MAAm 1 and MAAm/AMPS ${ }_{1}$ hydrogels have a more porous structure and open channels in contrast to $\mathrm{MAAm}_{2}$ and 
MAAm/AMPS ${ }_{2}$. Therefore, as seen in Table 2, where swelling values are presented, the polymeric network with a more porous structure facilitates the penetration of the water molecules and eventually increases the swelling values.
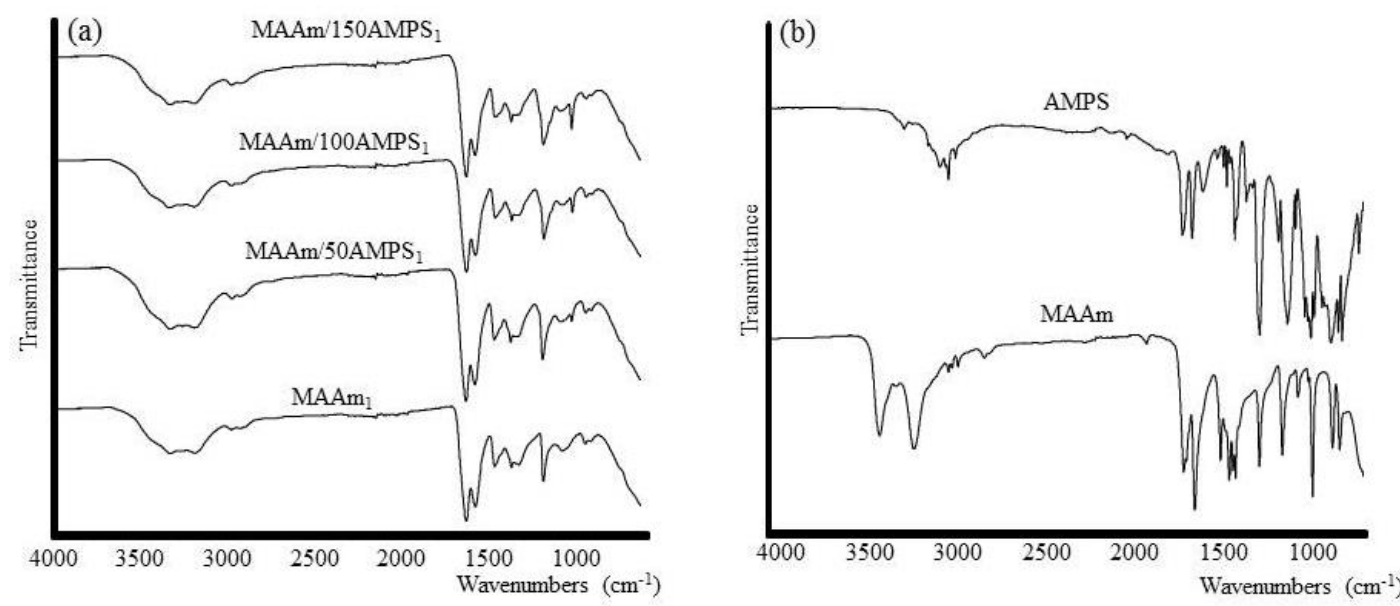

Figure 3. FT-IR spectra of polymeric hydrogels (a) and pure MAAm and pure AMPS (b)

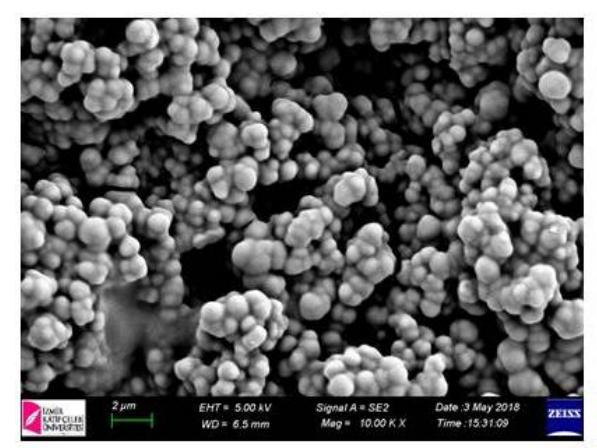

MAAm $_{1}$

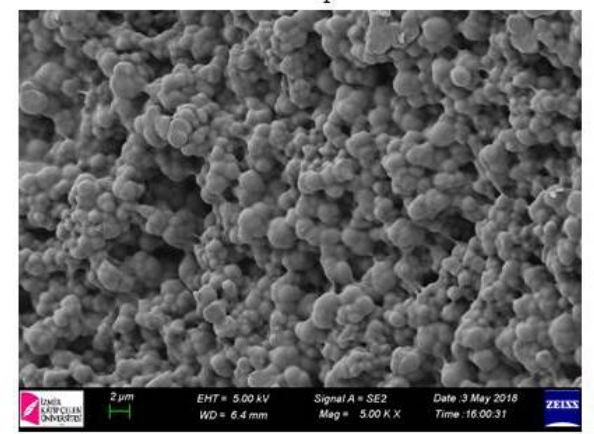

MAAm/100AMPS $_{1}$

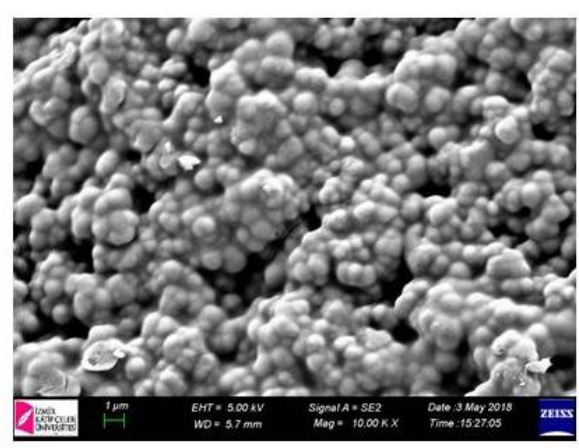

$\mathrm{MAAm}_{2}$

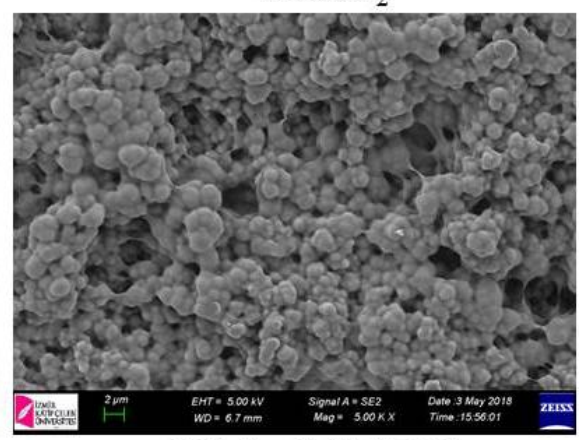

MAAm/100AMPS ${ }_{2}$

Figure 4. SEM micrographs for polymeric hydrogels

\section{Swelling studies}

Dry hydrogels exhibit swelling behavior when contacted with a suitable solvent. Among the properties of the polymer and solvent, there is a fundamental relationship affecting swelling. In the water bath where the temperature of $25^{\circ} \mathrm{C}$ was kept constant, swelling tests were performed at predetermined time intervals. Dry polymeric samples, pre-weighed and known their mass, 
were transferred to the beaker containing $40 \mathrm{~mL}$ of deionized water. Periodically surface water of samples removed from the water were dried by absorbent paper, weighed and then returned to the same swelling environment. The same process was continued until the time-invariant mass values were obtained.

The swelling values of hydrogels (PS\%) were calculated according to Equation 1 . (Kundakc1 et al., 2008; Pal et al., 2009; Karadağ et al., 2017).

$P S \%=\frac{m_{t}-m_{0}}{m_{0}} \times 100$

Here $m_{t}$ is the mass of water absorbed gel (at time $t$ ) and $m_{o}$ is the mass of the initial dry state of the gel $(t=0)$.

Water uptake of new MAAm-based MAAm/AMPS hydrogels crosslinked with NMBA was monitored, and the swelling isotherms calculated by Equation 1 were presented in Figure 5.

Figure 5 shows that the swelling increases over time until it reaches the equilibrium state and then remains constant. This constant swelling value is defined as the equilibrium percentage swelling value $\left(P S_{e q} \%\right)$ and is presented in Table 2 for all hydrogel systems.

Effect of monomer: The monomers used in the present work are the AMPS with hydrophilic groups and the MAAm having both hydrophilic and hydrophobic groups.

Firstly, the influence of AMPS on swelling properties of hydrogels was examined by varying the amount of AMPS (50-150 mg) added. Table 2 indicates that $P S_{e q} \%$ values of MAAm $_{1}$ hydrogels is $317 \%$ for samples but $P S_{e q} \%$ of MAAm/AMPS ${ }_{1}$ hydrogels are $456 \%-$ $1225 \%$ with the addition of AMPS units into MAAm hydrogels. The increase in swelling values was also observed in MAAm/AMPS 2 hydrogels by increasing the amount of AMPS as presented in Table 2. This is due to the fact that the AMPS units, which carry quite a number of hydrophilic groups, increase the hydrophilic character of the polymeric chain. Therefore, the increase of AMPS content in all copolymeric hydrogels resulted in an increase in $P S_{e q} \%$ values.

Secondly, when the amount of AMPS in hydrogel structures was kept constant $(100 \mathrm{mg})$ and MAAm was reduced to $0.75 \mathrm{~g}$, an increase in swelling results as shown in Table 2 was observed. With the decrease in the amount of MAAm, it can be considered that the increase in swelling values due to the decrease of hydrophobic groups in the structure of the hydrogel.
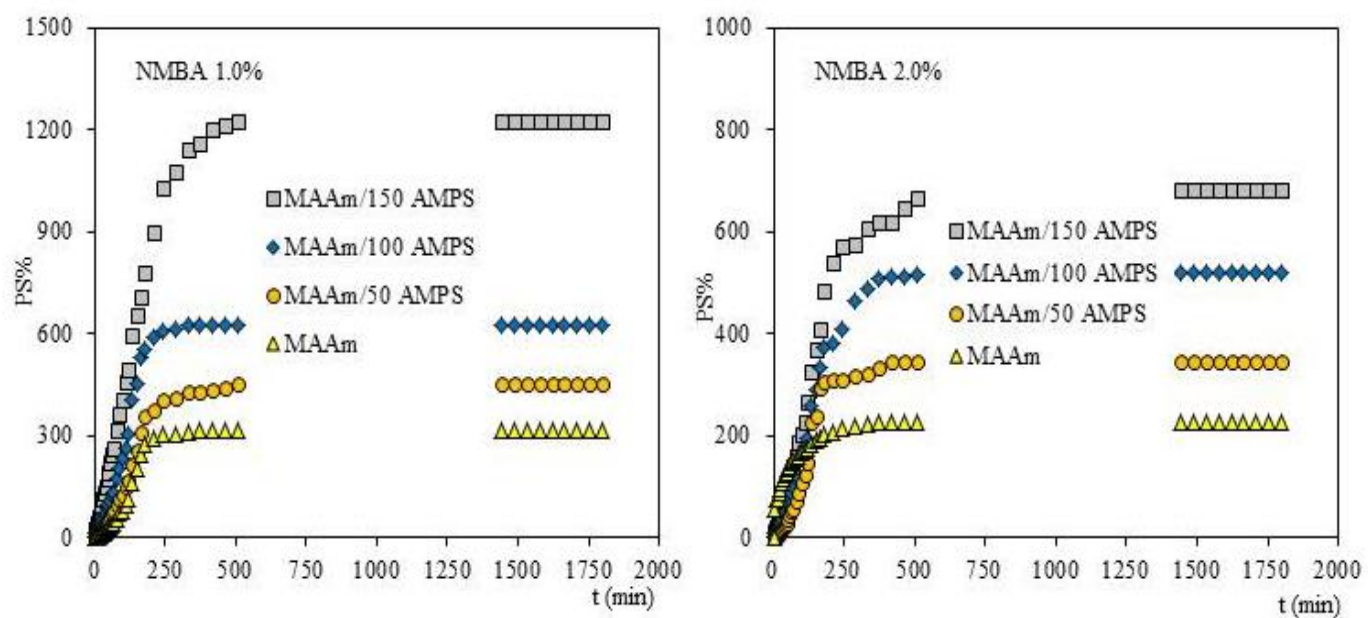

Figure 5. Swelling isotherms of polymeric hydrogels 
Table 2. Experimentally obtained parameters of MAAm and MAAm/AMPS hydrogels

\begin{tabular}{|c|c|c|c|c|c|c|}
\hline & Hydrogel & $\mathrm{PS}_{\mathrm{eq}} \%$ & EWC\% & $\mathrm{n}$ & $\mathrm{kx} 10^{3}$ & $\overline{D x 10^{5}}$ \\
\hline & $\overline{\text { MAAm }_{1}}$ & 317 & 76.01 & 1.6061 & 0.17 & 36.88 \\
\hline & 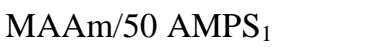 & 456 & 82.03 & 1.1526 & 1.43 & 39.43 \\
\hline 1 & 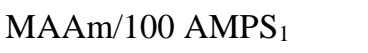 & 627 & 86.25 & 1.0810 & 2.41 & 46.33 \\
\hline & 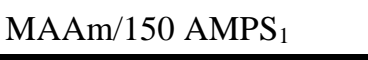 & 1225 & 92.46 & 0.9708 & 3.74 & 48.25 \\
\hline \multirow{4}{*}{2} & $\mathrm{MAAm}_{2}$ & 228 & 69.48 & 0.4721 & 0.16 & 10.17 \\
\hline & 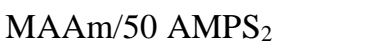 & 348 & 77.67 & 1.6153 & 0.19 & 68.82 \\
\hline & $\mathrm{MAAm} 100 \mathrm{AMPS}_{2}$ & 522 & 83.92 & 1.1596 & 1.48 & 42.15 \\
\hline & $\mathrm{MAAm} 150 \mathrm{AMPS}_{2}$ & 684 & 87.24 & 1.0173 & 2.89 & 36.05 \\
\hline \multirow{2}{*}{3} & $0.75 \mathrm{MAAm} / 100 \mathrm{AMPS}_{1}$ & 2095 & 95.44 & 1.0561 & 2.74 & 65.15 \\
\hline & $0.75 \mathrm{MAAm} / 100 \mathrm{AMPS}_{2}$ & 588 & 84.10 & 1.0695 & 2.93 & 23.00 \\
\hline 4 & $\mathrm{MAAm} / 100 / \mathrm{AMPS}_{1.5}$ & 602 & 85.76 & 0.9910 & 3.49 & 44.25 \\
\hline 5 & MAAm/0 AMPS $_{1.5}$ & 289 & 74.27 & 1.5775 & 0.40 & 57.62 \\
\hline
\end{tabular}

Effect of crosslinker: One of the factors affecting the swelling process in crosslinked copolymeric structures is the amount of crosslinker. In this study, NMBA with the hydrophilic properties as crosslinker was selected and the effect on swelling was investigated by using an amount ranging from $1.0 \%$ to $2.0 \%$. When the results presented in
Table 2 are examined, it can be observed that the increase in the amount of crosslinker in the hydrogel structures decreases the swelling values (Figure 6). The observed decrease in swelling values could be attributed to an increase in the crosslinking density which reduces the pore size of the hydrogel.

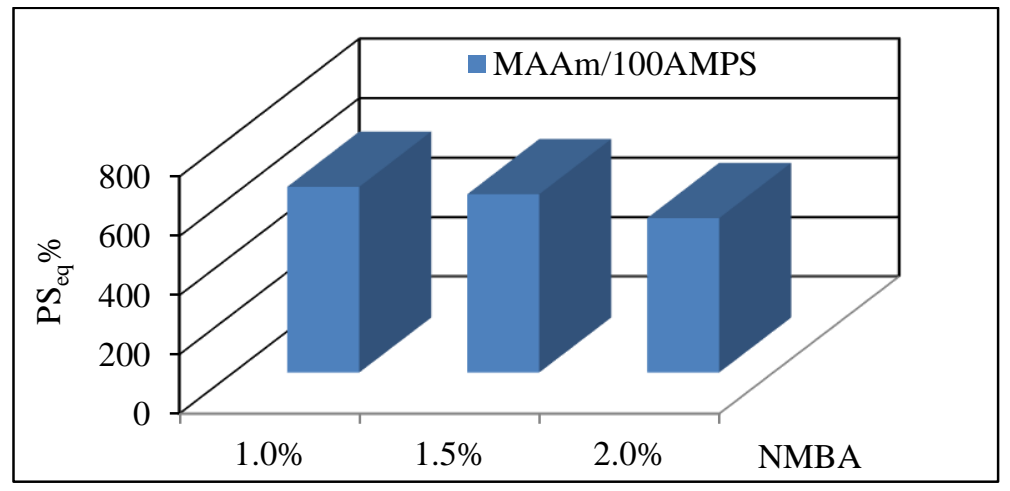

Figure 6. Influence of crosslinker amount on equilibrium swelling values

The amount of water contained in the equilibrium state of hydrogel systems is defined as the equilibrium water content $(E W C)$. The $E W C$ value calculated using Equation 2 provides a lot of information about the properties of polymeric gels such as permeability, mechanical property, surface property and biocompatibility (Pedley et al., 1980; Lee et al., 2000).

$E W C=\frac{\text { mass of water in the hydrogel }}{\text { total mass of swollen hydrogel }} x 100$
For all polymeric hydrogels presented in Table 2, the EWC values were found to range from $69.48-95.44 \%$. These values are quite compatible with the body's percent water content values $(60 \%)$.

The Fick equation presented in Equation 3 is used to study the diffusion of water to the polymer matrix.

$F=\frac{M_{t}}{M_{s}}=k t^{n}$ 
$F$ is the ratio of the amount of solvent that the gel receives at $t$ time to the amount of solvent it receives in equilibrium and is defined as a swelling fraction. Diffusional exponent $(n)$ and diffusion constant $(k)$ values were calculated by using graphs of the linearized form $(\ln F=\ln k+$ $n \ln t)$ of Equation 3 to explain the macromolecular network and penetrant properties as well as the transport mechanism.

The Fick diffusion equation is applied to the absorption in the first $60 \%$ of the diffusion of water to the macromolecule network. In the case where $n$ is 0.5 , the diffusion type is defined as Fickian diffusion and the diffusion rate is slower than the relaxation rate. If $n$ values are in the range of $0.5<n<1.0$, then diffusion is the type of non-Fickian diffusion which diffusion rate and the relaxation rate are simultaneously active. When the diffusion rate is greater than the relaxation rate, $n>1$ (Super Case II transport) (Ritger and Peppas, 1987; Dengre et al., 2000; Guilherme et al., 2015).

When Table 2 is examined, it is determined that the $\mathrm{n}$ values calculated for the purpose of explaining the transport mechanism of the water to the hydrogel network are greater than 1.0 (Super Case II transport). The Super Case II, the diffusion time of the water to hydrogels is greater than the relaxation.

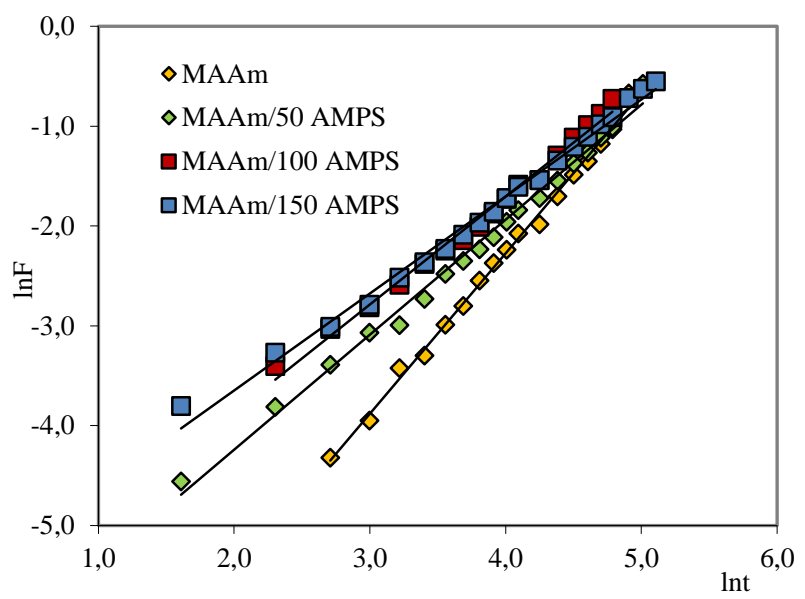

Figure 7. Graph of $\ln F$ versus $\ln t$ for the polymeric hydrogels (NMBA 1.0\%)

Investigation of water diffusion events in hydrogels is important for clarifying the polymer behavior. Diffusion coefficient values applied to hydrogels with cylindrical structure, which is an important parameter for hydrogel characterization, were calculated by using Equation 4. (Dengre et al., 2000).

$\mathrm{D}=\pi r^{2}\left(\frac{k}{4}\right)^{1 / n}$

Here, $D$ is the symbol of the diffusion coefficient $\left(\mathrm{cm}^{2} \mathrm{~min}^{-1}\right)$ calculated as the area of the polymeric hydrogel that the solvent molecules permeate per unit time, while $r$ is the symbol of the radius of the polymeric hydrogels having the cylindrical structure. $k$ and $n$ were previously described.

For all polymeric hydrogels synthesized in this study and presented in Table 2, the diffusion coefficient values vary between $10.17 \times 10^{-5} \mathrm{~cm}^{2} \mathrm{~s}^{-}$ ${ }^{1}-68.82 \times 10^{-5} \mathrm{~cm}^{2} \mathrm{~s}^{-1}$. The increase in the number of AMPS units in the hydrogel structure has led to an increase in the gel area through which the solvent molecules pass through the unit time. In addition, $D$ values decreased with increasing MAAm units and decreased with increasing amount of crosslinker. Dry and aqueous media appearance of chemically crosslinked hydrogel structures was presented in Figure 8. 


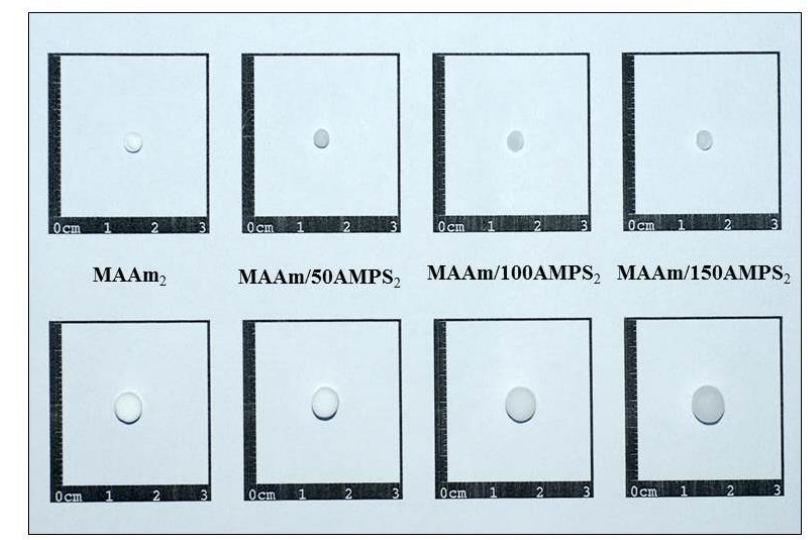

Figure 8. Dry (upper) and swollen (bottom) appearance of copolymeric hydrogels.

\section{CONCLUSION}

In recent years, polymeric structures with hydrogel matrix have been designed for various applications in different fields and their applicability has been investigated. One of the important characteristics of such hydrogels is their swelling behavior. The swelling parameters of the MAAm/AMPS hydrogels synthesized in this study were examined in terms of the amount of monomer and crosslinker. $\mathrm{PS}_{\text {eq }} \%$ values are $317 \%-1225 \%$ for MAAm/AMPS $_{1}$ (NMBA $1.0 \%$ ) and $228 \%-684 \%$ for $\mathrm{MAAm} \mathrm{AMPS}_{2}$ (NMBA 2.0\%). The increase in $\mathrm{PS}_{\mathrm{eq}} \%$ values in parallel with the increase in AMPS in all structures is thought to be due to the increase of hydrophilic groups in the polymeric structure. However, when the amount of MAAm and the amount of crosslinker were increased, the swelling values decreased. Equilibrium water content values, which is an important parameter for some biomedical applications, were found to be greater than $60 \%$ for all samples $(69.48 \%$ $95.44 \%$ ). Consequently, the MAAm/AMPS hydrogels developed in this study can be suitable for use in aqueous areas such as water treatment, agriculture, pharmaceuticals and biomedical applications where a polymeric carrier may be required.

\section{ACKNOWLEDGMENT}

This study was supported by Aydın Adnan Menderes University Scientific Research Projects (FEF 17017).

\section{REFERENCES}

Barati A, Asgari M, Miri T, Eskandari Z, 2013. Removal and recovery of copper and nickel ions from aqueous solution by poly(methacrylamide-co-acrylic acid)/montmorillonite nanocomposites. Environmental Science and Pollution Research, 20: 6242-6255.

Dengre R, Bajpai M, Bajpai SK, 2000. Release of vitamin B-12 from poly(N-vinyl-2pyrrolidone)-crosslinked polyacrylamide hydrogels: a kinetic study. Journal of Applied Polymer Science, 76: 1706-1714.

Durmaz S, and Okay O, 2000. Acrylamide/2acrylamido-2-methylpropane sulfonic acid sodium salt-based hydrogels: Synthesis and characterization. Polymer, 41: 36933704.

Ganji F, Vasheghani-Farahani S, VasheghaniFarahani E, 2010. Theoretical description of hydrogel swelling: A review. Iranian Polymer Journal, 19: 375-398. 
Guilherme MR, Aouada FA, Fajardo AR, Martins AF, Paulino AT, Davi MFT, Rubira AF, Muniz EC, 2015. Superabsorbent hydrogels based on polysaccarides for application in agriculture as soil conditioner and nutrient carrier: A review. European Polymer Journal, 72: 365-385.

Karadağ E, Yel B, Kundakcı S, Üzüm ÖB, 2017. Synthesis and application of acrylamide/sodium vinyl sulfonate/carboxymethylcellulose/zeolite hybrid hydrogels as highly swollen effective adsorbents for model cationic dye removal. Desalination and Water Treatment, 74: 402-414.

Koetting M, Peters JT, Steichen SD, Peppas NA, 2015. Stimulus-responsive hydrogels: Theory, modern advances, and applications. Materials Science and Engineering R, 93: 1-49.

Kousar F, Malana MA, Chughtai AH, Khan MS, 2018. Synthesis and characterization of methacrylamide-acrylic acid-Nisopropylacrylamide polymeric hydrogel: degradation kinetics and rheological studies. Polymer Bulletin, 75: 1275-1298.

Kundakci S, Üzüm ÖB, Karadağ E, 2008. Swelling and dye sorption studies of acrylamide/2-acrylamido-2-1-

propanesulfonic acid/bentonite highly swollen composite hydrogels. Reactive \& Functional Polymers, 68: 458-473.

Lee SJ, Kim SS, Lee YM, 2000. Interpenetrating polymer network hydrogels based on poly(ethylene glycol) macromer and chitosan. Carbohydrate Polymers, 41: 197205.
Pal K, Banthia AK, Majumdar DK, 2009. Polymeric hydrogels: Characterization and biomedical applications-A mini review. Designed Monomers and Polymers, 12: 197-220.

Pedley DG, Skelly PJ, Tighe BJ, 1980. Hydrogels in Biomedical Applications. The British Polymer Journal, 12: 99-110.

Peppas NA, Bures P, Leobandung W, Ichikawa $\mathrm{H}$, 2000. Hydrogels in pharmaceutical formulations. European Journal of Pharmaceutics and Biopharmaceutics, 50: 27-46.

Ritger PL and Peppas NA, 1987. Transport of penetrants in the macromolecular structure of coals. 7. Transport in thin coal sections. Fuel, 66: 1379-1388.

Singhal R and Gupta K, 2016. A Review: Tailormade hydrogel structures(classifications and Synthesis parameters). PolymerPlastics Technology and Engineering, 55:1, 54-70.

Sunitha K, Sadhana R, Mathew D, Reghunadhan Nair CP, 2015. Novel superabsorbent copolymers of partially neutralized methacrylic acid and acrylonitrile: Synthesis, characterization and swelling characteristics. Designed Monomers and Polymers, 19:6, 512-523.

Wan T, Xiong J, Zhao Q, Wu D, Tang L, Liao L, Chen Q, 2016. Crosslinker effects on swelling and gel properties of $\mathrm{pH}$-and temperature-responsive poly(NIPAM/IA/AM) hydrogels. Polymer Bulletin, 73:1447-1458. 